\title{
INFLUENCIANDO LEITORES, CONTRA TERRA PLANA: O ETHOS NA REVISTA SUPERINTERESSANTE ON-LINE
}

\author{
Influencing Readers, Against Flat Land: Ethos in the Online \\ Superinteressante Magazine
}

Eduardo PARÉ GLÜCK

Universidade do Vale do Rio dos Sinos eduardogluck@gmail.com https://orcid.org/0000-0001-5032-9582

Marcos Filipe ZANDONAI Universidade do Vale do Rio dos Sinos marcosfzan@gmail.com https://orcid.org/0000-0001-7731-8533

\begin{abstract}
RESUMO: Este artigo toma como objetivo principal investigar como se manifesta o ethos da instância de produção da informação em um artigo de opinião no escopo da divulgação científica midiática. Buscou-se, mais especificamente, verificar as estratégias que permitem ao locutor identificar-se com um ethos atrativo de ciência e favorável à sua racionalidade, segundo o contrato de comunicação de midiatização da ciência (CHARAUDEAU, 2016). Para acesso ao status do locutor, valemo-nos dos Modos de Organização Enunciativo e Argumentativo e do pathos (CHARAUDEAU, 2009b; 2010), nas formas textuais que elas assumem para corresponder ao gênero. Em uma abordagem qualitativa, os resultados mostram, por exemplo, duas tópicas globais no plano de texto, a da Repulsa e a da Antipatia, que, combinadas a outros recursos de captação, constroem um ethos de Identificação. O outro ethos identificado é o de Credibilidade. Juntos, os dois instrumentalizam a posição de aliança com o público identificado da revista e de oposição ao antifiador. PALAVRAS-CHAVE: Divulgação Científica Midiática; Ethos; Revista Superinteressante; Semiolinguística.
\end{abstract}

\begin{abstract}
This paper has as main objective to investigate how the ethos of the information production instance is manifested in an opinion article within the scope of scientific dissemination in media. More specifically, we sought to verify the strategies that allow the speaker to identify with an attractive ethos of science and, at the same time, favorable to its rationality, according to the mediatic scientific dissemination (CHARAUDEAU, 2016). In order to have access to the speaker's status, we use the enunciative and the argumentative modes of organization and the
\end{abstract}


pathos (CHARAUDEAU, 2009b; 2010), in the textual forms they take to meet the expectations of the genre. Under a qualitative approach, the results show, for example, two global topics in the text plan, the Repulsion and the Antipathy, which, combined with other funding resources, build an ethos of Identification. The other ethos identified is that of Credibility. Together, the two instrumentalize the position of alliance with the public identified of the magazine and of opposition to the anti-guarantor. KEYWORDS: Ethos; Mediatic Scientific Dissemination; Semiolinguistics; Superinteressante Magazine.

\section{INTRODUÇÃO}

Como influenciar/agir sobre o outro em um artigo de opinião com temática científica? Esta pergunta norteou a presente pesquisa, cujo objeto de análise consiste em um artigo de opinião publicado no blog Supernovas, da revista eletrônica Superinteressante, intitulado Não, Olavo: a água também não é plana (VAIANO, 2019). O objetivo é observar as imagens que o divulgador científico projeta de si (e, por extensão, da instância de produção, que envolve o site) de modo a obter "moral" ou legitimidade perante o público-alvo da sua argumentação.

De modo geral, os artigos de opinião tendem a expressar um ponto de vista sobre determinado tema notadamente polêmico, ligado a fatos recentes (CUNHA, 2012), e, assim, o articulista de uma revista como a Superinteressante deve realizar uma performance discursiva que denote a sua confiabilidade (uma imagem positiva de si), o que propicia o estudo do ethos. Investigam-se, aqui, procedimentos enunciativos que constroem esse ethos da instância argumentante ${ }^{1}$.

Este problema de pesquisa se justifica pelo fato de investigar, a partir das marcas enunciativas, o modo pelo qual o articulista interage com os leitores, evidenciando as estratégias empregadas por ele que permitem identificar suas opiniões a partir de um tema muito discutido, que é o da Terra Plana. O corpus aborda um tema polêmico (de a Terra e a água serem ou não planas) e bastante atual, explicitado já no título, o que favoreceria um campo textual de busca de influência, ligado, portanto, aos nossos objetivos.

\footnotetext{
${ }^{1}$ Ao assumirmos os postulados de Charaudeau (2009), incorporamos também a sua teoria dos sujeitos. Os seres de fala se enquadram ora em identidades psicossociais, ora em identidades discursivas. Interessados no ethos, daremos mais atenção à identidade discursiva que o articulista projeta em sua enunciação, motivo pelo qual, na seção Análise e resultados, o nomearemos prioritariamente de "enunciador". Mas, nos momentos em que enfatizamos os cálculos para ele "entrar" na enunciação, isto é, os dispositivos mais "externos" - comunicacional e social referimo-nos a esse mesmo sujeito como produtor textual e articulista, por exemplo.
} 
Essa polêmica é, no fundo, um mal-estar perante o qual alguns veículos - como a Superinteressante, por meio desse artigo - se veem coagidos a se posicionar, uma vez que a concepção de Terra Plana, baseada em teoria de conspiração, vai de encontro a pressupostos e proposições científicas bastante sedimentadas, que, aliás, continuam sendo atualizadas (PIRULLA, 2016). Dentro delas, o terraplanismo não entra. Ocorre que essa teoria conspiratória preenche lacunas, da incompreensão de conceitos científicos, e abraça certos valores ideológicos prévios; daí seu potencial para conversações, influência e discussão. No embate nós (terraplanistas) vs. o sistema (que oculta a "verdade"), os argumentos dos terraplanistas formam uma falsa polêmica, que distorce a observação da realidade (ao ignorar variáveis, por exemplo), mas que se sustenta porque os terraplanistas se posicionam como o outro em relação ao establishment (ALVIM, 2017; PIRULLA, 2016).

A escolha por este artigo opinativo também se dá porque ele nos permite avançar em análises sobre a atividade argumentativa stricto sensu da divulgação científica midiática (doravante DCM), haja vista que os estudos empreendidos pelo nosso grupo de pesquisa $^{2}$ têm se concentrado mormente sobre textos e sequências textuais de informação e explicação e não tanto sobre gêneros de finalidade argumentativa.

Na próxima seção, apresentar-se-á a fundamentação teórica que sustenta o presente artigo.

\section{NO QUADRO DA SEMIOLINGUÍSTICA: AS CONDIÇÕES DE PROVA}

Todo texto necessita de condições mínimas para que os sujeitos linguageiros se entendam, para que a comunicação chegue a algum lugar. Para isso servem os princípios de alteridade, pertinência, influência e regulação (CHARAUDEAU, 2005), os quais fazem o produtor textual pensar em que papéis linguageiros precisa adotar que justifiquem a sua tomada de palavra.

Em parte, os quatro princípios coercem o ato de linguagem, ao estabelecerem ditames para a comunicação, mas, por outro lado, fornecem ao produtor textual um conjunto de maneiras de dizer possíveis (GIERING, 2010). Esses princípios, em suma,

\footnotetext{
${ }^{2}$ O grupo de pesquisa Comunicação da Ciência: Estudos Linguístico-discursivos (CCELD), que dá origem ao presente trabalho, é coordenado pela Profa. Dra. Maria Eduarda Giering, e está vinculado ao Programa de Pós-Graduação em Linguística Aplicada da Universidade do Vale do Rio dos Sinos (UNISINOS).
} 
compõem o contrato de comunicação ${ }^{3}$, que é um jogo de regulação pelo qual os indivíduos se orientam e que codifica os dados da situação de comunicação, sendo que faz parte do contrato o pressuposto de que os sujeitos o levam em conta (CHARAUDEAU, 2009b).

A influência e a regulação servem para a margem de manobras, para o palco da "resposta" (às circunstâncias) ou output pela fabricação de certos ditos e significações em detrimento de outras instruções cabíveis. O nível discursivo é, por excelência, esse lugar de intervenção do sujeito falante, transformado em enunciador, por encenar o contrato, “devendo atender às condições de legitimidade (princípio de alteridade), de credibilidade (princípio de pertinência) e de captação (princípio de influência e de regulação), para realizar os 'atos de discurso' que resultarão num texto" (CHARAUDEAU, 2005, p. 17, grifos do autor).

A legitimidade (ou problemática do ethos) tem a ver com inspirar confiança e ter "certo poder de atração sobre o auditório" (CHARAUDEAU, 2007). O produtor textual, também pergunta-se como tocar o outro?, problemática do pathos (captação), e como organizar a descrição do mundo que propomos/impomos ao outro?, logos (CHARAUDEAU, 2007).

O ethos não advém apenas na legitimidade, isto é, da construção da alteridade, do eu discursivo em oposição ao antiethos (GIERING; GLÜCK, 2019; MENEZES, 2017; SILVA, 2010). Isso porque facilmente percebemos que o ethos (poder de atração, como dito antes) é também um gesto de regulação, não só de legitimidade. Ora, para influenciar e antecipar-se à contrainfluência (que é a natureza da regulação), o locutor se apropria de estratégias do nível discursivo, dentre as quais se situa a legitimidade (ethos), mas não só, como os estudos acima citados têm demonstrado. Desta maneira, não vemos o ethos isolado dos outros fatores; as estratégias do nível discursivo se imbricam. Apesar disso, buscamos nos concentrar, é claro, no ethos.

Assim, para "equipar" a eficácia do seu discurso, o locutor precisa regular, proceder à regulação. As propriedades do ethos que advêm desse princípio se concentram nas seguintes preocupações do locutor: (a) justificar a razão de sua tomada de palavra e (b) estabelecer um tipo de vínculo com o interlocutor que assegure esse lugar de direito (CHARAUDEAU, 2007). Então, esses fatores das condições de eficácia, mais ligados ao ethos, é que compõem o nosso recorte.

À segunda propriedade (item "b"), Charaudeau (2007) subsume os "rituais sóciolinguageiros" alocução, delocução e elocução, que justamente organizam posições e

\footnotetext{
${ }^{3} \mathrm{O}$ contrato de comunicação é um acordo, entre os sujeitos de discurso, sobre as representações linguageiras da prática social em que estão inseridos (CHARAUDEAU, 2009).
} 
comportamentos dos sujeitos (arranjos do tipo de relação). Esses rituais ocorrem, à luz de Charaudeau (2007), quando o enunciador entra em contato com o outro, tendo em vista que, para isso, ele recorre aos procedimentos de enunciação locutivos descritos acima, que estão em vigor no grupo social ao qual o enunciador pertence (CHARAUDEAU, 2007). Por isso, "a finalidade desse processo é a adesão às normas sociais de comportamento" (CHARAUDEAU, 2007, p. 5).

Sendo assim, o ato de linguagem não é totalmente consciente e é subsumido por um certo número de rituais socio-linguageiros, em que se combinam o dizer e o fazer. $\mathrm{O}$ fazer é o espaço da instância situacional que se define pelo lugar que ocupam os responsáveis desse ato (parceiros). O dizer é o espaço da instância discursiva que se define como uma encenação da qual participam seres de fala (protagonistas).

Esses dois vieses do processo de enunciação (justificar por que o locutor pode tomar a palavra e o estabelecimento de tipos de vínculo) são, aqui, privilegiadamente explorados, porque, segundo Charaudeau (2007), são construções subjacentes à prática de convencimento do auditório. Corporificam-se nas formas textuais da enunciação e da argumentação ${ }^{4}$.

Com essas premissas e recorte teóricos, passemos agora para o estatuto do ethos.

\section{A CONDIÇÃO DE PROVA - ETHOS}

Charaudeau (2007), ao investigar como o locutor se identifica discursivamente, reflete sobre o seguinte questionamento: "como impor sua pessoa de sujeito falante ao outro?”. Segundo Maingueneau (2001), por meio da enunciação, revela-se a personalidade do enunciador, isto é, o ethos discursivo do sujeito de fala, que é caracterizado como a forma pela qual quem escreve se enuncia. Eis o problema da identidade discursiva. Segundo Charaudeau (2009a):

a identidade discursiva tem a particularidade de ser construída pelo sujeito falante para responder à questão: 'Estou aqui para falar como?' Assim sendo, depende de um duplo espaço de estratégias: de 'credibilidade' e de 'captação'. A credibilidade está ligada à necessidade, para o sujeito falante, de que se acredite nele, tanto no valor de verdade de suas asserções, quanto no que ele pensa realmente, ou seja, em sua sinceridade. O sujeito falante deve, pois, defender uma imagem de si

\footnotetext{
${ }^{4}$ Estas são mais bem esmiuçadas na seção Comportamentos enunciativos e patemização, dedicadas, então, às marcas linguísticas do ethos.
} 
mesmo ('um ethos') [...] (CHARAUDEAU, 2009a, p. 316, grifo do autor).

Destarte, entendemos que a totalidade do ethos agrupa as três condições de eficácia do discurso (CHARAUDEAU, 2009a; MENEZES, 2017) já mencionadas. Consoante Maingueneau (2014, p. 267), "para dar essa imagem positiva de si mesmo, o orador pode mobilizar três qualidades fundamentais: a phronesis (prudência), a Arete (virtude) e a eunoia (benevolência)". O próprio Charaudeau (2006) assinala que as figuras identitárias que emergem em discursos políticos são arranjadas em dois grandes predicamentos de ethos: Credibilidade (discurso da razão) e Identificação (discurso do afeto). Charaudeau (2006) aplica esses conceitos no discurso político, no entanto, fazemos o aproveitamento desse arranjo teórico para a argumentação de outro contexto de comunicação também, como assim o faz Menezes (2017).

Silva (2010) se vale dessa categorização (Credibilidade e Identificação), demonstrando, em sua análise de um discurso político, que os ethé de Credibilidade - de sério, de virtude e de competência - exprimem as características técnicas do enunciador e a desqualificação do oponente. Por outro lado, os ethé de Identificação fundam-se mormente no sistema doxológico do público-alvo (SILVA, 2010). Nesse caso, as paixões entram em jogo, nas imagens de: caráter; inteligência (astúcia e malícia); humanidade (demonstrar sentimentos); e solidariedade (mostrar ajuda) (CHARAUDEAU, 2006; SILVA, 2010).

A leitura faz, então, emergir uma "instância subjetiva que desempenha o papel de fiador do que é dito" (MAINGUENEAU, 2001, p. 98). A qualidade do ethos remete, segundo o linguista, “à imagem desse 'fiador' que, por meio de sua fala, confere a si próprio uma identidade compatível com o mundo que ele deverá construir em seu enunciado" (MAINGUENEAU, 2001, p. 99). Assim, é por meio de seu próprio enunciado que o fiador deve legitimar sua maneira de dizer.

Mas como não existem marcas específicas do ethos (CHARAUDEAU, 2006), elegemos as categorias de acesso a ele a partir das premissas estabelecidas no penúltimo parágrafo da seção. No quadro da Semiolinguística, há necessidades de justificar-se e de estabelecer um tipo de relação com o destinatário. As categorias provêm dos Modos de Organização Argumentativo (para o primeiro caso, que é o justificar-se) e Enunciativo (para o segundo caso, dos comportamentos e especificações enunciativas) (CHARAUDEAU, 2009b).

Considerando o gênero discursivo artigo de opinião, adotam-se, aqui, elementos do Modo de Organização Argumentativo, porque o corpus parte de um quadro de 
questionamento (a validade das ideias de Olavo de Carvalho sobre a planicidade da Terra e da água). Por conseguinte, o enunciador elabora o estabelecimento da verdade, cujo fim será incutir certa verdade, como Proposta sobre o mundo (CHARAUDEAU, 2009b). Do ponto de vista do enunciador, a Proposição sobre o mundo se dá na persuasão contra o antifiador, mas a favor da ciência. Nessa troca linguageira com o público-alvo, o intuito é incutir uma verdade, como dito, e que o sujeito-alvo a aceite.

O problema é que o fazer racional (problematizar e provar a tese) e elucidativo (fazer compreender) sobre o mundo deve se combinar com os papéis que o enunciador atribui a si e a outrem (comportamentos enunciativos) e, ainda mais, com fatores patêmicos, que facilitariam a argumentação (CHARAUDEAU, 2004), a serem mais bem anotados na seção subsequente.

\section{COMPORTAMENTOS ENUNCIATIVOS E PATEMIZAÇÃO}

Para Charaudeau (2009b), no âmbito da análise do discurso, há três funções do Modo Enunciativo, que são: elocutiva (revelar o ponto de vista do locutor), alocutiva (estabelecer relação de influência entre locutor e interlocutor) e delocutiva (retomar a fala de um terceiro).

De acordo com Charaudeau (2009b, p. 83), na função elocutiva, "o sujeito falante enuncia seu ponto de vista sobre o mundo (o propósito referencial), sem que o interlocutor esteja implicado nessa tomada de posição". Isto é, quando se trata da função elocutiva, será levada em consideração a manifestação do "eu”, que, neste caso, é uma faceta particular do articulista (da enunciação), evidenciando como ele se coloca frente a seu interlocutor, como se relaciona consigo mesmo.

Na função alocutiva, segundo Charaudeau (2009b, p. 82), “o sujeito falante enuncia sua posição em relação ao interlocutor no momento em que, com o seu dizer, o implica e lhe impõe um comportamento". Em outras palavras, no que diz respeito à função alocutiva, será estudada a relação de influência, isto é, como o locutor age enunciativamente sobre o interlocutor.

Já na função delocutiva, segundo Charaudeau (2009b, p. 83), “o sujeito falante se apaga de seu ato de enunciação e não implica seu interlocutor. Ele testemunha a maneira pela qual os discursos do mundo se impõem a ele". Ou seja, na função delocutiva, será analisado como o enunciador "desaparece" no seu ato de enunciação, retomando a fala de um terceiro. Isso porque, nessa função, como no discurso relatado, a enunciação está desvinculada tanto do próprio enunciador quanto do interlocutor. Não há, portanto, a 
implicação do "eu" e do "tu"; apenas de um terceiro.

Dessa forma, considerando que estamos tratando de análise de um artigo de opinião, evidenciamos o modo pelo qual o enunciador se enuncia em relação ao interlocutor, a si mesmo ou a um terceiro.

No que concerne ainda às instruções discursivas que devem satisfazer à legitimação da tomada de palavra, investigamos o universo patêmico, isto é, "“[... um processo de dramatização que consiste em provocar a adesão passional do outro atingindo suas pulsões emocionais" (CHARAUDEAU, 2007, p. 245). Nesse escopo, o linguista faz o seguinte questionamento: "como tocar o outro?". Para responder tal pergunta, a partir de suas análises, o linguista cria

[...] quatro grandes tópicos, cada um duplamente polarizado, (de fato, negativo ou positivo, visto que a patêmica não é somente o sofrimento), e nomeia-se através de termos que não têm senão um valor emblemático: o tópico da "dor" e seu oposto, a "alegria"; o tópico da "angústia" e seu oposto, a "esperança"; o tópico da "anti-patia" e o seu oposto, a "simpa-patia"; o tópico da "repulsa" e seu oposto, a "atração" (CHARAUDEAU, 2010, p. 10-11).

Dessa forma, para o linguista, uma tópica é um tipo de argumento. Além disso, conforme postula Plantin (2018, p. 474), “uma tópica é um sistema empírico de coleta, de produção e de tratamento da informação para múltiplas finalidades (narrativa, descritiva, argumentativa), essencialmente práticas". Assim, a seguir, o Quadro 1 elucida as tópicas.

Quadro 1: Tópicas

\begin{tabular}{|l|l|}
\hline Polarização Negativa & Polarização Positiva \\
\hline Dor & Alegria \\
\hline Angústia & Esperança \\
\hline Antipatia & Simpatia \\
\hline Repulsa & Atração \\
\hline
\end{tabular}

Fonte: Elaborado pelos autores com base em Charaudeau (2010).

A cada uma dessas tópicas, Charaudeau (2010) atribui figuras particulares, as quais podem possuir variações de grau. Essas figuras encontram-se sintetizadas no Quadro 2, na sequência. 
Quadro 2: Figuras Particulares das Tópicas

\begin{tabular}{|l|l|}
\hline Tópica & Figuras (com variações de grau) \\
\hline Dor & $\begin{array}{l}\text { Tristeza, vergonha, incômodo, humilhação, } \\
\text { orgulho ferido. }\end{array}$ \\
\hline Alegria & Satisfação, contentamento, vaidade, orgulho. \\
\hline Angústia & Aborrecimento, medo, terror. \\
\hline Esperança & Confiança, desejo, votos, chamada, oração. \\
\hline Antipatia & $\begin{array}{l}\text { Indignação, acusação, denúncia, cólera, } \\
\text { ódio. }\end{array}$ \\
\hline Simpatia & Benevolência, compaixão, piedade. \\
\hline Atração & $\begin{array}{l}\text { Admiração, fervor, maravilhamento, } \\
\text { encantamento. }\end{array}$ \\
\hline Repulsa & Desprezo, desgosto, aversão, fobia. \\
\hline
\end{tabular}

Fonte: Elaborado pelos autores com base em Charaudeau (2010).

Por exemplo, a tópica da dor não corresponde à dor física, mas a um estado mental, do nível discursivo, como estado de insatisfação do desejo do sujeito (CHARAUDEAU, 2007).

Esses elementos linguísticos são interpretados à luz da esfera de midiatização da ciência - em que se inserem -, que faz valer um contrato de comunicação caracterizado pelo imbricamento das esferas científica, didática e midiática, cada qual contribuindo com preocupações e valores próprios (CHARAUDEAU, 2016), que resultam em um texto de DCM. O produtor textual, nesta esfera, vê-se obrigado a: (a) demonstrar evidências da verdade5 que pretende estabelecer, por meio da encenação de regras e axiomas, por influência do domínio especializado; (b) fazer compreender os acontecimentos, recorrendo à narratividade e à causalidade, por exemplo, devido ao dispositivo didático; e (c) dramatizar, espetacularizar, tornar o fato mais legível, como atos discursivos condizentes com a esfera midiática (CHARAUDEAU, 2016).

Esse contrato estabelece um quadro situacional-comunicacional, com os rituais e papeis linguageiros convenientes, que se corporificam em estratégias (de legitimação, credibilidade e captação) da parte do enunciador. Esse quadro situacional deve ser levado em conta juntamente com as características do gênero artigo de opinião (CUNHA, 2012).

Para que o projeto de influência tenha mais chances de obter êxito, o articulista 
desenvolve sua argumentação em uma revista de divulgação científica e no formato de um artigo de opinião. Esse gênero demanda, além das restrições contratuais referidas, que o locutor comente fatos recentes e polêmicos (que dividem as pessoas) (CUNHA, 2012). No caso do corpus, isso acontece por meio da referência às mensagens do sujeito delocutado, Olavo de Carvalho. Outrossim, o artigo de opinião apresenta maior tendência à assimetria entre os sujeitos, isto é, entre o locutor e o interlocutor, sendo que o locutor é endossado pelas instituições jornalística e acadêmica (CUNHA, 2012). Uma característica fundamental é que, em decorrência da natureza polêmica do artigo opinativo, esse status do articulista não basta para promover o convencimento, o que o leva a criar uma performance discursiva, com diálogo implícito ou explícito com as opiniões do antifiador (CUNHA, 2012); isto é, a construção do ethos contra o delocutado.

Esclarecido o nosso referencial teórico, passamos para a descrição da metodologia que foi empregada na pesquisa aqui relatada.

\section{METODOLOGIA}

O corpus desta pesquisa é um artigo de opinião publicado em 31 de maio de 2019 no blog Supernovas do site da revista Superinteressante. Esse artigo é escrito pelo jornalista Bruno Vaiano e intitulado Não, Olavo: a água também não é plana. O artigo está disponível no Anexo, apresentando-se segmentado, do número 1 (primeira proposição) ao número 65 (última proposição de seu texto), em unidades textuais de base, então demarcadas tipograficamente por terem um revestimento mínimo de predicação e serem investimentos mínimos de visada (expectativa ou finalidade discursiva). Ademais, essa segmentação facilita, para fins de análise, que façamos referência aos trechos do artigo pelos seus respectivos números de segmento. Embora tenhamos examinado o artigo em sua totalidade, encontram-se, no Anexo, apenas os segmentos mais representativos do relato analítico apresentado na seção Análise e resultados, devido à extensão do presente artigo. O link do texto analisado, na íntegra, está disponível no final da seção Anexo.

A análise do texto consistiu nas seguintes etapas: (i) levantamento de pistas que denotam a relação de influência do locutor sobre o alocutário e a construção de imagens sobre o próprio locutor e sobre a ciência (operadores argumentativos, modalizadores, tempos verbais etc.); (ii) identificação de relações qualitativas entre, de um lado, os itens linguísticos encontrados e, de outro, as propriedades da enunciação, da argumentação e do ethos (CHARAUDEAU, 2006; 2009b); (iii) indutivamente, agrupamento das evidências linguísticas relevantes em determinados ethé recorrentes, o que resulta em duas categorias 
de ethé: Credibilidade e Identificação; (iv) refinamento da análise textual, delimitando-se como categorias de acesso aos ethé as subsequentes: Modo de Organização Enunciativo, Modo de Organização Argumentativo e tópicas. As etapas ii e iii, em especial, realçam o trabalho de busca por regularidades, e, ainda, compatibilidades entre níveis de análise (CHARAUDEAU, 2005; 2009b).

No que diz respeito aos construtos que formam o ethos, procedemos a um movimento indutivo. Mas no exame da significância psicossocial do ethos, tornamos explícito o conhecimento já existente - em Silva (2010) e em Charaudeau (2006) -, em atuação empírico-dedutiva. No relato analítico que se abre na seção Análise e resultados, relacionamos microuniversos de sentido a dois projetos de ethos/influência.

\section{ANÁLISE E RESULTADOS}

\section{Ethé em prol do ethos de Credibilidade}

Logo no título do artigo, é possível notar o interesse em "fisgar" o leitor. Para esse propósito, chama atenção o marcador de pressuposição “também”: “(1) Não, Olavo: a água também não é plana" (VAIANO, 2019). O locutor intenta ser taxativo perante o antifiador, garantindo, desde já, que a água do mar não é plana. Ele afirma o conteúdo $a$ Terra não é plana sem declará-lo explicitamente, pois o marcador "também" denuncia a segurança epistêmica do enunciador. Já no título, portanto, ele se inclina a demarcar o território da "verdade" de um modo incisivo. Trata-se de uma marca da construção "realista" do macrotema, formato da Terra, na perspectiva do discurso científico, que fomenta esse regime do real.

O lead/resumo do artigo de opinião comporta outro marcador de pressuposição passível de desenhar, na mente do público, a tensão entre Olavo de Carvalho e Bruno Vaiano, ou seja, ciência vs. pseudociência, sob a perspectiva do artigo.

(2) A sugestão do filósofo autodidata foi refutada ainda no século 19 por Wallace, o "padrasto" da seleção natural. (3) Entenda com ajuda do método científico (VAIANO, 2019, grifo nosso).

Dizer que a sugestão de Olavo foi refutada ainda no século 19 equivale a dizer que Olavo está mais do que ultrapassado. Por meio do "ainda", o enunciador visa apequenar o oponente (de quem se fala), o que gera a encenação da tensão fiador versus antifiador, que, na perspectiva do primeiro, deve ser resolvida com o enfraquecimento do segundo. 
A avaliação sobre o pronunciamento de Carvalho impõe-se soberana, no modo elocutivo propriamente, visando ao enfraquecimento do sujeito delocutado no segmento 2 .

O título comporta o modo alocutivo, mas direcionada ao oponente, Olavo de Carvalho - o que talvez possa suscitar que os "afetados", os "interpelados", sejam seus defensores -, o que reafirma o cenário de embate.

Mas cumpre destacar o modo alocutivo também em outros segmentos do artigo de Bruno Vaiano, para além do momento inicial de problematização.

Em "Entenda com ajuda do método científico" (segmento 3), temos o verbo "entender" no imperativo. A relação alocutiva está para a categoria Injunção, em uma relação também de força sobre o outro, força que se justifica pelo cotexto, que aciona o método científico. Vários outros trechos se comportam assim, demonstrando a encenação da assimetria, como é o caso do segmento 13 - "Veja a ilustração de seu livro abaixo" -, que versa sobre as ideias do terraplanista Rowbatham.

Nesses modos de alocução voltados para o leitor, apontamos a forma afirmativa, derivada da Constatação, no que diz respeito à escolha enunciativa do produtor textual.

Outra operação favorável ao ethos de potência (conferido à ciência e aos cientistas) é a categoria numeral. O trabalho feito por cientistas sérios (a voz do eu-enunciador) é representado como mais significativo quantitativamente, como os exemplos a seguir confirmam.

(21) Ou seja: desde daquela época, Rowbotham está refutado - por Wallace, e por muitos outros experimentos realizados desde então [desde o século 19].

(39) Se dezenas de acadêmicos fazem dezenas de observações de um fenômeno e todas elas levarem às mesmas conclusões, é porque o grau de incerteza sobre aquele determinado fenômeno é bem baixa.

(54) A Terra é redonda, e isso não é bem uma teoria - está mais para fato, mesmo. [...]. (57) Há dezenas de fotos e experimentos que confirmam essa observação [por observação, leia-se "a Terra é redonda"] (VAIANO, 2019, grifo nosso).

Trazer ao texto as vozes de outros especialistas (modo delocutivo) confere ainda mais atrativo ao ethos almejado pelo enunciador. Nota-se o apagamento do ponto de vista do enunciador por meio de verbos de elocução, verbos de processo mental ou nomes ilocucionários. As propriedades semânticas desses verbos e nomes permitem que estabeleçamos a divisão credibilidade versus não credibilidade (Quadro 3). 
Quadro 3: Modo delocutivo Credibilidade versus Não credibilidade

\begin{tabular}{|c|c|}
\hline Credibilidade - suporte ao articulista & Não Credibilidade - terraplanismo \\
\hline $\begin{array}{c}\text { Wallace percebeu que o experimento de } \\
\text { Rowbatham não levava em consideração o } \\
\text { fenômeno (...) (segmento 18) }\end{array}$ & $\begin{array}{c}\text { A sugestão do filósofo autodidata (segmento } \\
\text { () }\end{array}$ \\
\hline $\begin{array}{c}\text { Popper logo se deu conta de que a ciência } \\
\text { havia esquecido suas próprias limitações } \\
\text { (segmento 35) }\end{array}$ & $\begin{array}{c}\text { Samuel Rowbotham afirmou que havia } \\
\text { comprovado a planicidade (segmento 9) }\end{array}$ \\
\hline $\begin{array}{c}\text { De acordo com a definição do Centro } \\
\text { Nacional para Educação Cientifica dos } \\
\text { EUA, um fato é (...) (segmento 55) }\end{array}$ & $\begin{array}{c}\text { Rowbotham hipotetizou que ele o veria } \\
\text { desaparecer atrás da linha do horizonte } \\
\text { (segmento 11) }\end{array}$ \\
\hline Nas palavras de Stephen Jay Gould, de & $\begin{array}{c}\text { Olavo ignora o conceito de falseabilidade } \\
\text { (segmento 23) }\end{array}$ \\
Einstein entrou, substituiu a de Newton \\
(segmento 53)
\end{tabular}

Fonte: elaborado pelos autores a partir de trechos de Vaiano (2019).

Ora, os verbos de elocução e mentais ou nomes ilocucionários atribuídos a cientistas não terraplanistas adquirem maior assertividade do que aqueles da coluna da não credibilidade, o que contribui para a encenação argumentativa, como mostra o Quadro 3. Dão, aliás, mais corpo ao ethos de virtude do enunciador, pois ele as assume como verdadeiras, as assume em suas Propostas e Interpelações (alocutivamente, como visto) e em suas Constatações (elocutivamente, ao enunciar o Saber), tendo destinatários e antifiador como receptor de obrigação ou testemunhas.

Com efeito, não só os verbos e nomes ilocucionários atuam no efeito de credibilização, no dualismo referido, como também as credenciais das instâncias citadas, pois, de um lado, há um “filósofo autodidata” e, do outro, há um Centro de Educação Científica e a Universidade de Harvard.

A instância argumentante não se constitui apenas de virtude credível, porquanto, para o interlocutor a aderir ao lado da ciência, Vaiano precisa mostrar o modo de vida atraente e palatável da ciência, como se vê a partir da próxima subseção.

\section{Ethé em prol do ethos de Identificação}


Bruno Vaiano joga com elementos congruentes à legitimidade, para obter status perante o público da Superinteressante, pois, como vimos na fundamentação teórica, a legitimidade está associada ao princípio da alteridade (CHARAUDEAU, 2005).

Por exemplo, no segmento 7 (primeiro comentário de Vaiano sobre a fala de Olavo), Bruno Vaiano joga com a ironia ao usar as expressões "felizmente" e "no mínimo", como se vê:

(7) Felizmente para o Olavo, ele está no mínimo um século atrasado: muita gente já fez as necessárias "observações e comparações" - tanto sobre a hipótese mais restrita da água plana quanto sobre a hipótese mais abrangente da Terra plana (VAIANO, 2019, grifo nosso).

Olavo diz que precisaria de meses, mas o locutor, em tom debochado, usa o paralelismo irônico: Olavo teria que atravessar um século para chegar ao que almeja. Esse recurso faz parte do movimento de desaprovação levado a cabo no artigo, já que o enunciador não concorda com a opinião de Olavo de Carvalho. A ironia suscita a tópica Repulsa: não é que Olavo esteja errado, "só” está no século errado, do ponto de vista do enunciador. Os operadores "no mínimo" e "já" colaboram para enfatizar essa pequenez do antissujeito.

Além disso, no segmento 22, a marca linguística depreciativa "inútil” também apela para a tópica da Repulsa.

(22) Esse debate, porém, não é de todo inútil. (23) Ao afirmar que precisaria de muito mais observações e experimentos para saltar da hipótese da água plana para a hipótese da Terra plana, Olavo ignora o conceito de falseabilidade introduzido à filosofia da ciência pelo austríaco Karl Popper na década de 1930 (VAIANO, 2019, grifo nosso).

Essa estratégia, como postula Charaudeau (2007), é susceptível de ter um efeito patêmico, estando nesse movimento de desaprovação. O enunciador diz que a hipótese da planicidade da água e a guerra de visões têm alguma utilidade, pois trazem a vantagem de se discutir sobre o que é necessário para algo ter validade cientificamente. Isso vai ao encontro da tópica global do texto, a Repulsa, pois o enunciador intenta "destruir" a hipótese dos terraplanistas.

Além do mais, de modo a auxiliar na tópica Repulsa, o enunciador utiliza o operador argumentativo "de todo", pois, na perspectiva do enunciador, a ciência não é um dogma, mas se nutre de debates. Ao dizer que a polêmica não é "de todo" inútil, o 
enunciador implicitamente (por pressuposição) admite a inutilidade da ideia de Olavo.

A ironia reside também em "argumento sensato", que carrega o subentendido o argumento não é correto, somente sensato: "(6) Olavo foi taxado imediatamente de terraplanista, mas refutou o rótulo com um argumento sensato: "Na minha profunda miséria intelectual [...]" (VAIANO, 2019, grifo nosso).

Esses marcadores de implicitude chamam atenção, por se referirem ao funcionamento da ciência. Servem de identificação do enunciador com o seu público presumido. Com efeito, os implícitos só são possíveis devido ao consenso de base - que permite veicular informações como se fossem "óbvias". Deste modo, o público "crítico", pela prefiguração do enunciador, captaria as ironias e o signo do embate, da condição de prova legitimidade-alteridade (nós, da ciência, contra eles, terraplanistas). Trata-se, aí, de "conquistar respeito e admiração do auditório" por meio de malícia e astúcia (SILVA, 2010).

A especificação enunciativa (Modo Enunciativo) é a de um enunciador superior ao sujeito delocutado (Olavo de Carvalho). Isto porque, após o discurso relatado no segmento informacional 6, ou seja, após a delocução, o enunciador incorpora a modalidade elocutiva de Opinião, emitindo um parecer sobre a fala de Olavo. Seu ponto de vista é marcado por itens argumentativos na proposição 7, e é nessa proposição mesmo que o enunciador distancia-se (por Opinião) do delocutado e não implica o interlocutor, testemunha da Opinião, o que indica a asseveração.

Enveredando-nos para outra seara de sentido, passamos para o segmento 26, a partir do qual o enunciador propõe-se a explicar por que o pronunciamento de Olavo é uma Ignorância, o que implica (na elocução via Saber) explicar a falseabilidade no mundo da ciência.

(26) Vamos explicá-la com um exemplo bobo: esquilos. (27) Suponha que você seja um biólogo e queira provar que todo esquilo tem rabo. (28) Você pode viajar o mundo fotografando todos os esquilos que for capaz de encontrar, e verificar em primeira mão que todos têm rabo. [...]. (VAIANO, 2019).

A partir desta macroproposição explicativa (segmento 26 ao 42), enumeramos marcas linguísticas que denotam o trabalho didático do articulista (no Quadro 4). O Quadro 4 exibe a ocorrência e seu efeito de sentido em termos de contribuição ao ethos. 
Quadro 4: Evidências do ethos de Identificação

\begin{tabular}{|c|c|}
\hline Trecho do corpus & Comentário analítico \\
\hline $\begin{array}{l}\text { “(26) Vamos explicá-la com um exemplo } \\
\text { bobo: esquilos. [...]”. }\end{array}$ & $\begin{array}{l}\text { O locutor propõe-se a esclarecer a noção } \\
\text { de falseabilidade. A analogia explícita } \\
\text { (esquilos) e o anúncio de que o exemplo } \\
\text { é "bobo" (qualificação) funcionam para o } \\
\text { enunciador manifestar-se como "descendo } \\
\text { do pedestal", como quem diz "ok, eu } \\
\text { simplificarei a informação para você, } \\
\text { leitor". }\end{array}$ \\
\hline $\begin{array}{l}\text { “(59) A ciência é um mecanismo que } \\
\text { regula a si próprio, a teoria de Newton foi } \\
\text { substituída pela de Einstein sem muitos } \\
\text { resmungos quando uma se provou ser uma } \\
\text { descrição da realidade mais precisa que a } \\
\text { outra". } \\
\text { "(2) A sugestão do filósofo autodidata foi } \\
\text { refutada ainda no século } 19 \text { por Wallace, o } \\
\text { "padrasto" da seleção natural”. } \\
\text { "(31) A falseabilidade é uma rédea; um } \\
\text { limite que evita que os cientistas abusem de } \\
\text { sua própria autoridade". }\end{array}$ & $\begin{array}{l}\text { Metáforas ou hipérboles mostram que o } \\
\text { locutor faz o trabalho de aproximar-se do } \\
\text { leitor. }\end{array}$ \\
\hline $\begin{array}{l}\text { “(32) Popper viveu em uma era marcada } \\
\text { por resquícios do positivismo - uma força } \\
\text { ideológica que defendia a supremacia do } \\
\text { conhecimento científico sobre toda forma } \\
\text { de superstição e crença religiosa”. }\end{array}$ & $\begin{array}{l}\text { A reformulação metadiscursiva (segmento } \\
\text { 32) e demais recursos descritivos para } \\
\text { o nome "positivismo" (introduzido no } \\
\text { segmento informacional 32) servem para } \\
\text { fazer compreender e para fazer crer que essa } \\
\text { corrente de pensamento foi um abuso. }\end{array}$ \\
\hline $\begin{array}{l}\text { "(19) Isso ocorre com o Sol todos os dias, } \\
\text { como você pode ver no esquema abaixo. } \\
{[\ldots] " .}\end{array}$ & $\begin{array}{l}\text { Há também recursos visuais para o locutor } \\
\text { garantir que o leitor permaneça na leitura e } \\
\text { se sinta cooperado. }\end{array}$ \\
\hline
\end{tabular}

Fonte: elaborado pelos autores.

Do Quadro 4, destacamos, na sequência, alguns aspectos do ethos de Identificação.

Quanto à explicação sobre o que é positivismo (segmentos 32 a 34), chama atenção o fato de o locutor procurar se aproximar do alocutário pelo viés da patemização. 
(32) Popper viveu em uma era marcada por resquícios do positivismo - uma força ideológica que defendia a supremacia do conhecimento científico sobre toda forma de superstição e crença religiosa. (33) O positivismo, inclusive, influenciou a proclamação da República no Brasil e os dizeres na nossa bandeira atual (VAIANO, 2019).

O período 33 avisa aos leitores que uma filosofia - como aquela surgida da França não necessariamente fica circunscrita à ciência, podendo alastrar-se para outros domínios da vida, e de maneira negativa. A inferência é: o mesmo poderia acontecer com a Terra plana, devido à não aplicação da falseabilidade. Esse parágrafo, juntamente ao parágrafo do segmento 34, permite inferir que, para o enunciador, Olavo e seus similares, ao não usarem o diálogo, ao não usarem a falseabilidade, cairiam no autoritarismo. Portanto, ao contrário deles, o enunciador, na medida em que sensibiliza(-se), "vende" a virtude do não autoritarismo científico.

O enunciador procura mostrar-se mediador competente e amigável, solidário, tanto que realiza injunções/interpelações elucidativas, apoiadas em ilustrações ao longo do artigo (elementos contemplados no Quadro 4), levando à acessibilidade do conteúdo.

\section{Síntese dos resultados}

Os resultados mostram os procedimentos de convencimento que constroem o ethos de Credibilidade, que agrupa os ethé de competência e de sério. Também revelam que a mobilização de paixões e que a imagem de inteligente (astuto e irônico) constituem o ethos de Identificação. Esses dados vão ao encontro do que foi verificado por Silva (2010) a respeito do comportamento do ethos em gênero argumentativo. Para edificar os dois ethé no corpus, as operações dos Modos de Organização Enunciativo e Argumentativo aparecem; e, em particular, na Identificação, as tópicas são convocadas.

A Credibilidade, de um lado, responde à problemática como impor minha palavra ao outro? Também é questionamento intrínseco à construção do ethos o como justificar as razões de minha tomada de palavra?. Este passa a ser respondido na medida em que o locutor marca território: "sou da ciência". Esses fatores homologam o quadro de influência e de regulação. Pelo princípio da regulação, o ethos do artigo é um constante marcar território contra o antifiador, haja vista que esse princípio consiste do controle do projeto de influência em uma atividade linguageira que seria, a priori, agonal (CHARAUDEAU, 2007).

Mas também é problema posto ao enunciador o como tocar o outro? (Identificação). 
Por essa via, ressalta-se a doxa e, por consequência, a construção de sentidos vai se orientando pelo princípio de alteridade, a qual, para Charaudeau (2007) se materializa nas estratégias de camaradagem e sensibilização, que constatamos.

Os tipos do ethos constatados constituem o aparato estratégico do locutor, pois lhe permitem dar conta do estatuto situacional e comunicacional: (i) as restrições discursivas da DCM, corporificada na Superinteressante on-line; (ii) a finalidade de esclarecimento; e (iii) a prática de convencimento que o gênero escolhido demanda. Consequentemente, os procedimentos empregados pelo locutor apontam para cenas e ethé (deboche, ironia, fidelidade às evidências) que seriam compatíveis com os valores que a instância de produção reivindica. Isto é, os modos de dizer, alimentados pela situação, justificam o porquê de o enunciador engajar-se nessa instância (por que é "melhor" o fiador ao antifiador).

Ao percorrermos o ethos, constatamos os cálculos e prefigurações para sua ingrediência: astúcia, repulsa, aliança (com interlocutores e/ou antifiador) e o comprometimento com a Credibilidade, todos construindo o ethos de força/virtude, em nome da ciência, contra o antissujeito. No fundo, o artigo de opinião encena o ethos de aliança com a ciência (atrativa e rigorosa) e, por extensão, com os interlocutores, subordinados ou em concordância ao ethos. Esse desequilíbrio, com a força/virtude no primeiro polo, é resolvido discursivamente pelas especificações enunciativas, operadores argumentativos e tópicas apontados.

A configuração possível de ethos no corpus seria mais bem representada com a legitimidade (aspirar confiança e mostrar "moral") entendida como faceta que é propulsionada pelos dois outros elementos: o logos e o pathos.

Como o nível comunicacional sobre determinaas instruções de sentido, é razoável ponderar que o enunciador seguro e virtuoso, que se depreende da análise, só é possível dadas as condições do artigo de opinião: a necessidade de ele estar indexado à ciência e a possibilidade maior de planejamento da escrita e pesquisa das fontes. A enunciação de Olavo de Carvalho, por seu turno, é feita no Twitter, contexto de maior informalidade e efemeridade, que não favorece a elasticidade de tempo que Bruno Vaiano (2019) tem para construir o poder e o saber.

\section{CONSIDERAÇÕES FINAIS}

A pesquisa aqui relatada indica o quanto as categorias analíticas apresentadas em Charaudeau (2006) para o discurso político servem a outros tipos de corpora e, 
assim, torna possível avançar no estudo das conversações polêmicas da Internet e das controvérsias envolvendo ciências (e pseudociências), pois é dessa bifurcação que se erige o ethos do nosso corpus. Esse ethos se firma na medida em que se desconstrói o delocutado oponente, algo que acontece também no artigo de opinião examinado por Menezes (2017).

É possível, ainda, ampliarmos os corpora, incluindo outras temáticas de mundo comentado que envolvem o embate e a busca por desconstrução do delocutado. Acreditamos que este artigo contribui para que os estudos de DCM se enveredem pela questão dos debates controversos, pois divulgadores têm entendido como cada vez mais necessária a tomada de posição contra fakenews e teorias da conspiração (PIRULLA, 2016).

O presente artigo pode auxiliar na elaboração de intervenções pedagógicas que focalizem os múltiplos letramentos em situação escolar, "didatizando-se" os fenômenos de argumentação aqui discutidos. Considerando os procedimentos discursivos de influência, regulação e alteridade, é viável, ainda, abordar a questão das relações empáticas nas discussões da Internet e a legitimidade dos atores que enunciam as "verdades" que nela circulam. Isso leva-nos à necessidade de questionar, na prática de leitura, análise e produção de textos que condições de produção e circulação proporcionam a confiabilidade das informações e que recursos de linguagem tendem a ser significativos na detecção de fakenews e pseudociência. 


\section{REFERÊNCIAS:}

ALVIM, Mariana. Quem são e o que pensam os brasileiros que acreditam que a Terra é plana. BBC Brasil, São Paulo, 16 set. 2017. Disponível em: <https://www.bbc.com/ portuguese/brasil-41261724>. Acesso em: 15 abr. 2020.

CHARAUDEAU, P. A argumentação talvez não seja o que parece ser. In: GIERING, M. E.; TEIXEIRA, M. Investigando a linguagem em uso: estudos em linguística aplicada. São Leopoldo: Ed. Unisinos, 2004.

Uma análise semiolinguística do texto e do discurso. In: PAULIUKONIS, M. A. L.; GAVAZZI, S. (Orgs.). Da língua ao discurso: reflexões para o ensino. Rio de Janeiro: Lucerna, 2005, p. 11-29. 2006 .

Discurso político. Trad. Fabiana Komesu e Dilson da Cruz. São Paulo: Contexto,

Pathos e discurso político. In: MACHADO, I. L.; MENEZES, W.; MENDES, E. (Org.). As Emoções no Discurso. Rio de Janeiro: Lucerna, 2007, p. 240-251.

- Identidade social e identidade discursiva, o fundamento da competência comunicacional. In: PIETROLUONGO, M. (Org.). O trabalho da tradução. Rio de Janeiro: Contra Capa, 2009a, p. 309-326.

Linguagem e discurso: modos de organização. Coord. Trad. Angela M. S. Corrêa e Ida Lúcia Machado. São Paulo: Contexto, 2009b.

A patemização na televisão como estratégia de autenticidade. In: MENDES, E.; MACHADO, I. L. (Org.). As emoções no discurso. Vol. II. Campinas: Mercado das Letras, 2010, p. 23-56.

. Sobre o discurso científico e sua midiatização. Calidoscópio, v. 14, n. 3, p. 550556, set./dez. 2016.

CUNHA, G. X. A articulação discursiva do gênero artigo de opinião à luz de um modelo modular de análise do discurso. Filologia e Linguística Portuguesa (Online) (USP), n. 14, v. 1, p. 73-97, 2012.

GIERING, M. E. Semiolinguística, enunciação e contexto de comunicação: o caso da notícia de divulgação científica dirigida a crianças. Cadernos de Pesquisas em Linguística (PUCRS), v. 5, n. 1, p. 126-137, 2010. 
GIERING, M. E.; GLÜCK, E. P. Ethos discursivo e o comportamento enunciativo: a construção de si de comentaristas de notícias de divulgação científica da revista Superinteressante online. Letras de Hoje (PUCRS), Porto Alegre, v. 54, n. 3, p. 385-394, jul./set. 2019.

MAINGUENEAU, D. Análise de textos de comunicação. 2a ed. São Paulo: Cortez, 2001. Discurso Literário. São Paulo: Contexto, 2014.

MENEZES, M. R. Ethos: Uma desconstrução possível pelo pathos. In: GOUVÊA, L. H. M. (Org.). Argumentação pela emoção: um caminho para persuadir. Rio de Janeiro: UFRJ, 2017, p. 89-120.

PIRULlA. Terra Plana e o Filtro pra Teorias da Conspiração. Publicado pelo Canal do Pirulla. S. I., 17 fev. 2016.1 vídeo (30 min 40 s). Disponível em: <https://www.youtube. com/watch?v=yzY7swaTwmA>. Acesso em: 15 abr. 2020.

PLANTIN, C. Tópos. In: CHARAUDEAU, P.; MAINGUENEAU, D. Dicionário de Análise do Discurso. São Paulo: Contexto, 2018. 500p.

SILVA, A. M. A imagem por trás do mito: estratégias discursivas e construção do ethos no discurso populista de Getúlio Vargas. 2010. Dissertação (Mestrado em Letras) - Faculdade de Filosofia, Letras e Ciências Humanas da Universidade de São Paulo (USP), São Paulo, 2010 .

VAIANO, B. Não, Olavo: a água também não é plana. In: Superinteressante. São Paulo, 31 mai. 2019. Disponível em: <https://super.abril.com.br/blog/supernovas/nao-olavo-aagua-tambem-nao-e-plana/>. Acesso em 30 jun. 2019. 


\section{ANEXO - TEXTO INTITULADO NÃO, OLAVO: A ÁGUA TAMBÉM NÃO É PLANA}

\section{(1) Não, Olavo: a água também não é plana}

(2) A sugestão do filósofo autodidata foi refutada ainda no século 19 por Wallace, o "padrasto" da seleção natural. (3) Entenda com ajuda do método científico.

(4) Tudo começou nesta quarta-feira, 29 de maio, quando Olavo de Carvalho escreveu o seguinte no Twitter: "Não estudei o assunto da terra plana [...]".

(6) Olavo foi taxado imediatamente de terraplanista, mas refutou o rótulo com um argumento sensato: "Na minha profunda miséria intelectual, para eu saltar desses experimentos para a teoria geral da terra plana eu precisaria de muitos meses de observações e comparações."

(7) Felizmente para o Olavo, ele está no mínimo um século atrasado: muita gente já fez as necessárias "observações e comparações" - tanto sobre a hipótese mais restrita da água plana quanto sobre a hipótese mais abrangente da Terra plana.

(8) Tudo começou no século 19 , em um trecho de $9,7 \mathrm{~km}$ de um rio retificado artificalmente, localizado no condado de Cambridgeshire, ao norte de Londres, na Inglaterra. (9) Em 1838, Samuel Rowbotham - uma personalidade terraplanista da época, que largou a escola aos nove anos e atendia pelo pseudônimo "Paralaxe" - afirmou que havia comprovado a planicidade das superfícies aquáticas em um experimento realizado por lá.

(11) Se a Terra de fato fosse curva, Rowbotham hipotetizou que, conforme o barco se afastasse rio abaixo, ele o veria desaparecer atrás da linha do horizonte. (13) Veja a ilustração de seu livro abaixo:

FIG. 2.

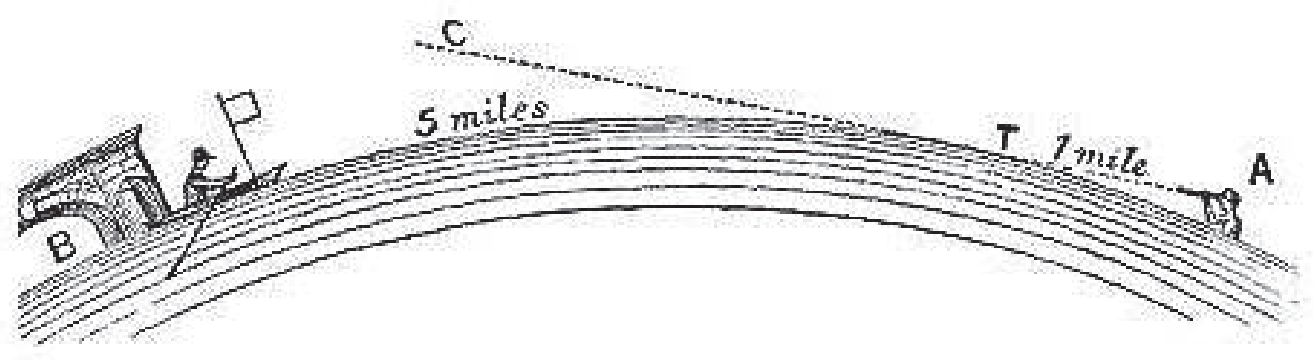

(18) Wallace percebeu que o experimento de Rowbotham não levava em consideração o fenômeno óptico bem-estabelecido da refração da luz pela atmosfera, que 
curva os raios e faz que objetos razoavelmente distantes pareçam estar mais acima da linha do horizonte do que realmente estão.

(22) Esse debate, porém, não é de todo inútil. (23) Ao afirmar que precisaria de muito mais observações e experimentos para saltar da hipótese da água plana para a hipótese da Terra plana, Olavo ignora o conceito de falseabilidade, introduzido à filosofia da ciência pelo austríaco Karl Popper na década de 1930.

(26) Vamos explicá-la com um exemplo bobo: esquilos. (27) Suponha que você seja um biólogo e queira provar que todo esquilo tem rabo. (28) Você pode viajar o mundo fotografando todos os esquilos que for capaz de encontrar, e verificar em primeira mão que todos têm rabo. (29) Na visão de Popper, porém, este corpo sólido de observações não será suficiente para afirmar que todo esquilo tem rabo - pois sempre há a possibilidade de que, no único parque que você não visitou, haja um esquilo sem rabo. (30) E o tal esquilo anômalo, sozinho, é suficiente para derrubar a hipótese.

(31) A falseabilidade é uma rédea; um limite que evita que os cientistas abusem de sua própria autoridade.

(32) Popper viveu em uma era marcada por resquícios do positivismo - uma força ideológica que defendia a supremacia do conhecimento científico sobre toda forma de superstição e crença religiosa. (33) O positivismo, inclusive, influenciou a proclamação da República no Brasil e os dizeres na nossa bandeira atual.

(34) Ele assistiu ao darwinismo social e à deturpação da genética pela eugenia de Francis Galton, que culminariam com o Holocausto. (35) Popper logo se deu conta de que a ciência havia esquecido suas próprias limitações - e precisava de rédeas assim. (36) Caso contrário, qualquer um poderia vender por aí a ideia de que a Terra é plana.

(37) Com a falseabilidade em campo, um cientista não pode afirmar nada com certeza absoluta. (38) Só está ao seu alcance reduzir ao máximo a incerteza sobre um assunto. (39) Se dezenas de acadêmicos fazem dezenas de observações de um fenômeno e todas elas levarem às mesmas conclusões, é porque o grau de incerteza sobre aquele determinado fenômeno é bem baixa. (40) Há 99,9\% de chance de que as conclusões sobre o tal fenômeno sejam verdadeiras. (41) Mas, para que a teoria tenha validade cientifica, ela precisa ser falseável. (42) É obrigatório que exista a possibilidade de encontrar um esquilo sem rabo, mesmo que ela jamais se realize.

(53) Já a gravidade em si é um fato.

(55) A Terra é redonda, e isso não é bem uma teoria - está mais para fato, mesmo. 
Adaptação de: <https://super.abril.com.br/blog/supernovas/nao-olavo-a-aguatambem-nao-e-plana/>. Acesso em: 13 jan. 2019.

Recebido em: 02 fev. 2020

Aceito em: 18 abr. 2020 